\section{The New World}

T The founders of American independence included several highly learned people who encouraged the study of mathematics and science in the late 18 th century.

Benjamin Franklin (1706-90) invented the Franklin stove, bifocal spectacles, the odometer, and the lightning rod. He also carried out experiments in electricity, such as his celebrated one on lightning conduction in which he flew a kite in a thunderstorm. Although never claiming to be a mathematician, he was fascinated by magic squares, and constructed a remarkable $16 \times 16$ square in which the numbers in any row, column, or $4 \times 4$ sub-square, have the same sum.
Thomas Jefferson (1743-1826), the third president of the United States, extolled the virtues of science and wrote of the importance of calculation (extracting roots, solving quadratic equations, and using logarithms). Interested in classical architecture, he designed his home, Monticello, and the rotunda of the University of Virginia. While ambassador in Paris he became enthused by the metric system being proposed in France, and strongly advocated decimalising the American coinage, but it was not until 1866 that the United States Congress passed a law legalising the use of metric measurements.

Benjamin Banneker (1731-1826) was a self-taught mathematician and astronomer. When 22 years old he designed and built an accurate striking clock, although he had never seen one previously. In later life he constructed accurate astronomical tables. In 1791 he compiled the first of several almanacs, as 'the creation of a free man of the African race', and sent it to Jefferson with a plea to end slavery. Banneker was appointed by George Washington, himself a noted surveyor, to help with the surveying and layout of the new capital city.

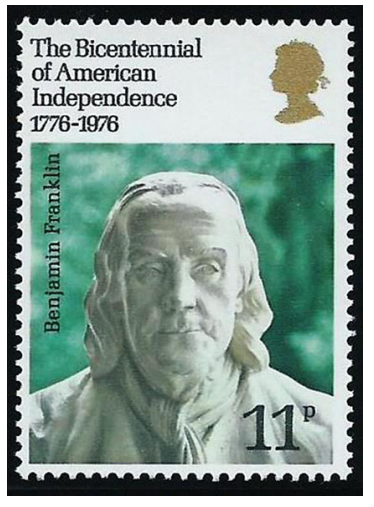

Benjamin Franklin

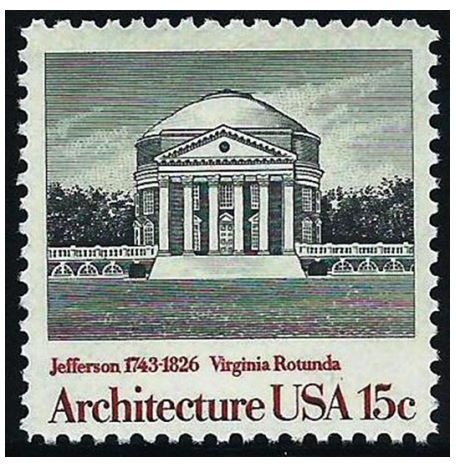

Virginia rotunda

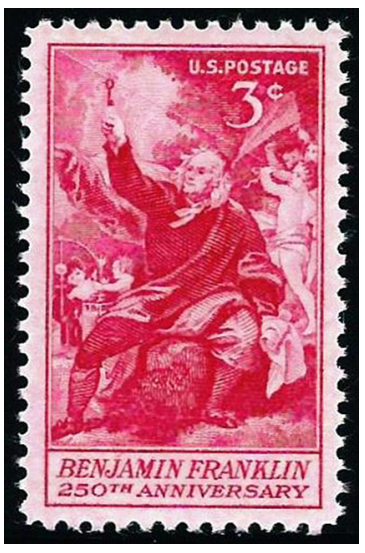

\section{Franklin's lightning experiment}

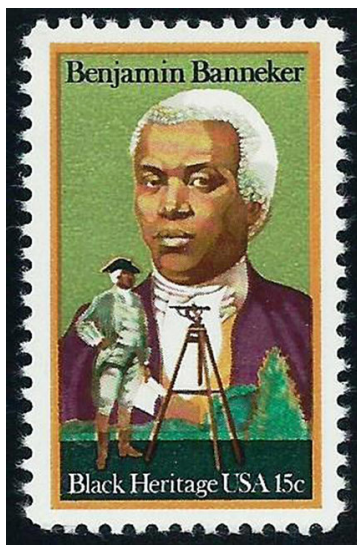

Benjamin Banneker

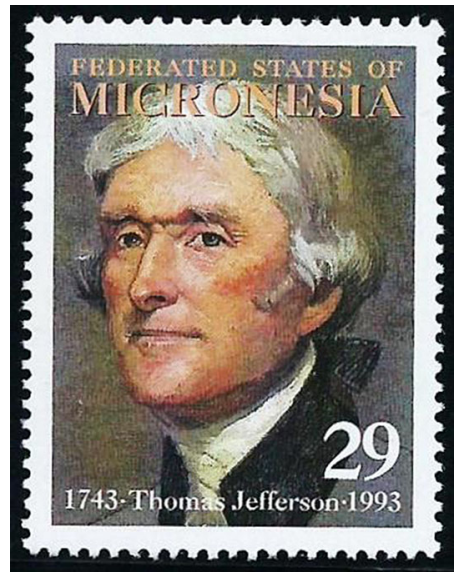

Thomas Jefferson

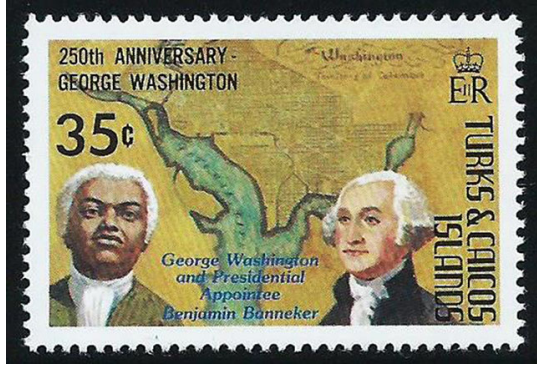

Banneker and Washington

> Column editor's address: Robin Wilson, Mathematical Institute,

Andrew Wiles Building, University of Oxford, UK

e-mail: r.j.wilson@open.ac.uk 